\title{
Rapid range shifts in African Anopheles mosquitoes over the last century
}

3 Colin J. Carlson ${ }^{1,+, *}$, Ellen Bannon ${ }^{2, *}$, Emily Mendenhall $^{2,3}$, Timothy Newfield ${ }^{1,4}$, Shweta Bansal $^{1}$

5 Affiliations:

$6 \quad{ }^{1}$ Department of Biology, Georgetown University, Washington, DC 20057, U.S.A.

$7 \quad{ }^{2}$ Science, Technology, and International Affairs Program, Edmund A. Walsh School of Foreign

8 Service, Georgetown University, Washington, DC 20057, U.S.A

$9 \quad{ }^{3}$ Developmental Pathways for Health Research Unit, Faculty of Health Sciences, University of 10 the Witwatersrand, Johannesburg, South Africa

$11{ }^{4}$ Department of History, Georgetown University, Washington, DC 20057, U.S.A.

$12 †$ Corresponding author: cjc322@georgetown.edu

$13 *$ These authors contributed equally.

15 Abstract

17 Anopheles mosquitoes are the vector of malaria and several neglected tropical diseases, such as

18 lymphatic filariasis and O’nyong'nyong fever. Like many species, mosquitoes are expected to

19 track warming temperatures in a changing climate, possibly introducing disease into previously

20 protected higher-latitude and higher-elevation communities. Tracking range shifts is fundamental

21 for forecasting disease risk, but has proven challenging to do in real-time. Here, we use historical

22 data to trace those shifts in Anopheles for the first time. We test for range shifts using a new

23 comprehensive dataset of Anopheles occurrences in sub-Saharan Africa, with over 500,000

24 species-locality pair records spanning 1898 to 2016 . We propose a simple regression-based 25 method of measuring range shifts in larger datasets, which identifies a more coherent signal in 26 anopheline range shifts than the Mann-Whitney method popular in ecology. We estimate range-

27 shifting species gained 1.56 meters of elevation annually, and moved southward $6.28 \mathrm{~km}$ per 28 year in their outer range limits, a full order of magnitude faster than some "rapid" shifts observed 29 in the literature. We expect these results to have major implications for malaria control work in 30 sub-Saharan Africa, and for our broader picture of vector responses to climate change. 


\section{Introduction}

33 In the coming century, scientific consensus predicts a massive redistribution of global

34 biodiversity, including the reservoirs, vectors, and pathogens that are most consequential to

35 human health. [1-3] A seminal 2011 study estimated that species are moving higher in elevation and latitude at a median rate of roughly 11 meters per decade and 17 kilometers per decade, respectively [4]; crop pests and pathogens have been estimated to be moving at a slightly faster pace of roughly 3 kilometers a year. [5] But despite the widespread model prediction and oftrepeated assumption that mosquitoes and other human disease vectors will track climate change, very little work explicitly documents these shifts, with no mosquitoes included in the 2011 estimate. Perhaps the most is known about the global expansion of Aedes aegypti and Ae. albopictus, which a recent study suggests have expanded up to 250 and 150 kilometers per year respectively. [6] But these are some of the best-documented vector ranges [7], and their rapid velocity is indicative of several global wavefronts of invasion in new landscapes, not climate change acting on equilibrium ranges. Almost no data exists on range shifts of non-invasive mosquitoes, and we know of no studies documenting a long-term signal in Anopheles mosquitoes, the vectors of malaria worldwide.

The genus Anopheles (Diptera: Culicidae) contains roughly 460 species of mosquito found on every inhabited continent. Roughly one quarter of species have the ability to transmit infectious diseases, including O'nyong'nyong virus, lymphatic filiariasis, and most significantly malaria (Plasmodium spp.). Malaria vectors exist all over the world, but the majority of the disease burden, especially from the most clinically severe species (P. falciparum), lies in subSaharan Africa. In 2017, of the 219 million cases of malaria worldwide, 92\% of cases and 93\% of deaths occurred in sub-Saharan Africa. [8] As for most vector-borne diseases, the severity and stability of malaria is determined by a handful of interacting and often covarying sociecological factors, including poverty, primary healthcare, migration, land use change, and climate. [9] As a result of heterogeneity in these factors, the burden of malaria is heavily clustered in national and regional hotspots; in 2017, Nigeria, the Democratic Republic of the Congo, Mozambique, India, and Uganda alone accounted for almost half of all cases. [8] As a consequence of vector and pathogen limits, areas of lower temperatures and higher elevation have historically been

61 protected from malaria [9], especially in East Africa (Burundi, Eritrea, Ethiopia, Kenya, Rwanda, 
62 and Tanzania) and isolated mountain ranges in countries like Cameroon, the DRC, and

63 Zimbabwe. [10] However, in a changing climate, many fear warming temperatures may allow

64 malaria to infiltrate these high altitude regions.

65 The problem of documenting range shifts in malaria is complicated by the semi-

66 independence of the pathogen, the vector, human populations, and underlying changes in

67 climate, land use, healthcare, and drug resistance. Since the $20^{\text {th }}$ century, several explosive

68 epidemics of malaria have been observed at high elevations in east Africa. [11,12] In the early

692000 s, researchers proposed increases in these outbreaks might be driven by a changing climate

70 [13], but some originally argued these trends were weak [14], or were driven by emerging drug

71 resistance and failures of vector control, and not climate change. [15,16] Over time, these data

72 been carefully re-evaluated alongside new evidence, with current consensus largely indicating

73 temperature-linked elevational shifts in malaria in countries such as Burundi, Ethiopia, Kenya,

74 Rwanda, and Uganda. $[9,17,18]$ The thermal bounds of malaria transmission are now fairly well

75 resolved [19,20], and most studies project that areas suitable for malarial transmission will

76 experience net increases across sub-Saharan Africa, and low-temperature areas protected from

77 malaria will contract significantly. [21-24] But most climate models of Plasmodium simply

78 assume mosquito range shifts will not be a limiting factor [22], and most work has focused on

79 malaria incidence separate from vector range boundaries.

80 Despite a handful of anecdotal records noting mosquito arrival at higher elevations [25],

81 no broad evidence as yet exists documenting anopheline mosquito range shifts. In this study, we

82 follow an approach common in global change biology [26] to test for evidence of range shifts in

83 historical records of mosquito occurrences. We focus on Anopheles mosquitoes in sub-Saharan

84 Africa, specifically on the dominant vectors of malaria. We test the idea that mosquitoes are

85 moving southwards (away from the equator) and upwards (gaining elevation), by looking for a

86 historical signal of mosquito range changes in the $20^{\text {th }}$ century. (We focus on range shifts at the

87 southern margin, measured in absolute latitude, given that the Sahel poses a hard dispersal

88 barrier in most cases.) In answering these, we aim to provide what we believe is the first data-

89 driven estimate of the velocity of mosquito range shifts at a continental scale, outside of those

90 occurring during a global biological invasion. [6] 
Data

96 To investigate evidence of range shifts in Anopheles mosquitoes, we used a recently published

97 compendium of occurrence data, focused on sub-Saharan Africa over the interval 1898 to 2016.

98 [27] These data are a compendium of several sources, including both deliberate methodic records

99 (entomological surveys from malaria research and control programs) and opportunistic data

100 collected incidentally to other research projects. Data sources include such a mix of carefully

101 maintained datasets, technical reports, theses and individual studies, and archival records that it

102 is difficult to generalize any uniform sampling biases in the data over space and time. There are

103 noticeable variations in completeness of the data due to the Global Malaria Eradication

104 Programme (1955-1969) and subsequent neglect of malaria projects in Africa for several

105 decades. (Figure S1) However, even when attention shifted elsewhere in the post-GMEP era,

106 over 5,000 species-locality pairs were generated every year-an essentially unparalleled depth of

107 data for such a narrowly defined taxonomic group.

108 To format these data for our study, we expanded every survey with a start and end year

109 one or more years apart into a separate record for every year. We eliminated all secondary

110 vectors and concatenated records of dominant vector presence as separate occurrences in

111 year/location pairs. This produced a total of 504,314 unique records from 48 countries, spanning

1121898 to 2016. For elevational data, we used the GTOPO30 global digital elevation model (DEM)

113 downloaded as a 30 arc-second resolution grid for Africa from Data Basin (www.databasin.org).

114 We extracted elevation for each distinct occurrence record, using the 'raster' package in $\mathrm{R}$

115 version 3.3.2.

\section{Region delineation}

119 For elevation analyses, we aggregated countries into four regions of Sub-Saharan Africa, defined

120 based on the Global Burden of Disease study and previously used to describe population at risk

121 from mosquito-borne disease. [28] Those regions are:

122 - Central Africa: Angola, Central African Republic, Democratic Republic of the Congo, 123 Equatorial Guinea, Gabon, Republic of Congo 
- East Africa: Burundi, Comoros, Djibouti, Eritrea, Ethiopia, Kenya, Madagascar, Malawi, Mozambique, Reunion, Rwanda, Somalia, South Sudan, Sudan, Tanzania, Uganda, Zambia, Mayotte, Zanzibar

- Southern Africa: Botswana, Lesotho, Namibia, South Africa, Swaziland, Zimbabwe

- West Africa: Benin, Burkina Faso, Cameroon, Cape Verde, Chad, Cote d'Ivoire, Gambia, Ghana, Guinea Bissau, Liberia, Mali, Mauritania, Nigeria, Niger, Guinea, Sao Tome and Principe, Senegal, Sierra Leone, Togo

\section{Models}

Our study design reflects the need for comparable estimates of elevational and latitudinal shifts to most animal and plant species, allowing us to avoid a handful of methodological problems. First, by focusing only on southward latitudinal shifts, we avoid the question of what the maximum traveling speed of Anopheles ranges is in any direction, which would require more complicated approaches, like spatial generalized additive models or kernel methods. Second, we assume that Anopheles ranges started as close to equilibrium as any other species did in the $20^{\text {th }}$ century, and that their spread did not follow a traveling wave-front. [6,29] By making this assumption, we focus on simple linear and directional trends in range shifts, and largely avoid any questions about underlying patterns of resistance on the landscape, or "points of introduction" (which would be a poor model for the underlying process). Finally, we assume that the question of interest is range margin shifts and not range core shifts, which would reflect more of the complex geography of malaria across African nations and over a century of social shifts. [30] Future work could potentially follow on this by using methods which test for, and then fit, unimodal curves in response to environmental gradients like elevation. [31] Within these constraints, we chose to try two basic methods of testing for range shifts. The first is adapted from the classic ecological literature on climate-driven range shifts, and involves using a Mann-Whitney $\mathrm{U}$ test to compare the top or bottom $n$ values (usually $\mathrm{n}=10$; see studies cited in [4]) of elevation or latitude between two non-overlapping intervals. The range shift velocity assigned is the difference in means divided by the time between the midpoints of the two intervals. While this method became extremely popular in the first decade of the 2000s [31-34], it comes with clear disadvantages, namely that it is designed for the kind 
155 of resurveys that are common in community ecology. For continuously-recorded data, it has two

156 forms of information loss: first in the aggregation of discrete years into intervals, and second in

157 the discarding of data in-between the intervals.

158 As a simple alternative to the Mann-Whitney approach, we propose a comparatively

159 simple, regression-based approach loosely adapted from Bebber et al. [5], in which the

160 maximum $n$ points (for elevation or latitude) are taken every year and analyzed using regression,

161 with species as a fixed effect, and with year nested within species. The number of points used

162 represents a tradeoff between using a few points capturing the most extreme values, which give

163 the best approximation of where range edges lie, and using more data, which increases statistical

164 power but also risks muddling the distinction between the range core and the range edge. In the

165 main text we use $n=3$ points, which already increases the number of records used over an order

166 of magnitude from the Mann-Whitney method. However, in the supplement we show the same

167 analyses using $n=10$, and using an optimal linear estimator as a "distance-to-edge" model. [35]

168 We used the new 'rangeshifts' R package to implement both of these analyses. In both

169 approaches, we applied a significance cutoff of $p=0.05$ to determine whether range shifts were

170 significant. For elevation and latitude, we used Mann-Whitney tests to compare species ranges

171 based on a baseline before the start of the Global Malaria Eradication Programme, and ten years

172 after it ended to the present (1898-1955 vs. 1979-2019). We only used the Mann-Whitney

173 approach to test for significance, and not to quantify range shift speed, given the large period of

174 aggregation we used. For elevation, we repeated the Mann-Whitney method separating countries

175 into five regions (North, West, East, Central, and Southern Africa), delineated based on the

176 Global Burden of Disease study regions.

177 We then analyzed both elevation and latitude using regression approach, with the

178 maximum $n=3$ points from every year. For elevation, we treated geographic divisions as a

179 random effect to account for spatial heterogeneity in the landscape (and the fact that several

180 elevational fronts can be expanding within a single range). Here, we decided our data was

181 complete enough — and Africa is a large enough continent — that we used country as that random

182 effect. (This also allowed us to decompose range shifts in a way we could not with the Mann-

183 Whitney tests - with 49 countries and 26 species represented in the dataset, there would be a

184 total of 1,274 possible pairwise comparisons.) 


\section{Results}

Our models suggested that the majority of species have experienced at least some range shift over the past few years. Using the Mann-Whitney approach for maximum latitude, we found that 16 species exhibited a significant global shift including two significant contractions (northwards towards the equator). For maximum elevation, 17 of 26 exhibited a significant global shift,

192 including six contractions (downwards). It is possible that the sign-reversed shifts represent

193 actual range shifts driven by vector control either during the Global Malaria Eradication

194 Programme (GMEP) or occurring since, corresponding to an overall century-long reduction in

195 Plasmodium falciparum prevalence due in at least some part to vector control. [30] It is equally

196 plausible, though, that they are an artefact of the crude Mann-Whitney approach and the

197 information loss that is required to run it.

By region, results of the Mann-Whitney tests on elevation were even more mixed. In West Africa, 6 species (out of 21 with enough data to run comparisons) had a significant shift, all being range expansions. In East Africa, 13 of 22 total were significant, including 8 expansions and 5 contractions. In Central Africa, 10 of 13 were significant, but only 2 were expansions. Data was most limited in Southern Africa, where five of seven possible tests were significant, and all were contractions. Overall, these results offer little cohesive explanation of long-term trends, and

204 highlight the downside of the interval comparison method-especially in the number of species 205 which had to be omitted due to sample size issues.

The linear regression approach, on the other hand, painted a more cohesive picture. For

207 latitude, we found that 24 out of 26 species had a significant trend (adjusted $R^{2}=0.947$ ); all but

208 two were negative. (Figure 2) Species with a significant trend displayed an average ( \pm s.e.) range

209 velocity of $6.28 \pm 1.4 \mathrm{~km}$ per year $(5.92 \pm 1.21$ for all species regardless of species:year intercept

210 significance). For elevation, in the mixed-effects model (conditional $R^{2}=0.674$ ), we found that

21122 species had a significant trend, of which 19 were positive. (Figure 3) Species had an average

212 significant range shift of $1.56 \pm 0.3$ meters per year (for all species: $1.27 \pm 0.27$ ). We found no

213 significant correlation between latitudinal and elevational shift (Figure 4), possibly suggesting

214 different traits predispose those shifts (per a similar finding by [34]), or that species do not differ

215 in dispersal capacity, and are probably tracking local climate and anthropogenic landscapes. 


\section{Discussion}

219 Our study presents compelling — and concerning — evidence of rapid range shifts in anopheline

220 mosquitoes. At a surprising maximum pace of 3.8 meters per year in elevation and 20 kilometers

221 per year in latitude, these shifts are more than an order of magnitude greater than others

222 considered "rapid" for climate-driven shifts. [4] While still an order of magnitude less than the

223 maximum speeds observed during the invasion of Aedes aegypti and Aedes albopictus in Europe

224 and the United States [6], ours are the first estimates that set the pace of native range shifts, a

225 process that is almost universally slower. In comparison to prior estimates of the velocity of

226 climate change in Africa (with a maximum around $10 \mathrm{~km}$ per year; [36]), our results suggest that

227 mosquitoes - especially the vectors most responsible for the burden of malarial disease-will

228 have little trouble keeping pace with shifting thermal optima. While this largely agrees with

229 modeling projections, it challenges the long-standing idea in historical epidemiology that

230 mosquito ranges are mostly stationary over decades, centuries, or millennia. [37,38]

Previous studies have either focused on modeling vector shifts or pathogen shifts [39],

232 and many models of vector-borne illness have been qualified by a disclaimer that worst-case

233 scenarios assume the presence of mosquitoes, without much certainty or data about their range

234 expansions. Without apparent dispersal constraints on mosquitoes, evidence seems unanimous

235 that most tropical and sub-tropical areas previously protected from vector-borne disease are

236 likely to experience the onset of new health regimes in the immediate future. These projections

237 agree with those made in parallel work on arboviruses, which has predicted future expansions in

238 high-altitude and high-latitude areas for chikungunya, dengue, Zika, and other illnesses. Within

239 countries, prioritization schemes for vector control and surveillance will have to change rapidly

240 to include new at-risk areas. In Ecuador, for example, models have projected that under the most

241 extreme climate change scenarios, the range of the Aedes aegypti mosquito should expand 4,215

$242 \mathrm{~km}^{2}$ into mountainous terrain, impacting over 12,000 people. [40] But at the global scale, the

243 number of countries facing these problems will also increase, with Aedes aegypti and Ae.

244 albopictus expected in 159 and 197 countries by 2080. [6] As Anopheles shift to the south and to

245 higher elevations, they will similarly produce new regional populations at risk from malaria,

246 lymphatic filariasis, and other pathogens. 
Mosquito range shifts during the $20^{\text {th }}$ century were influenced by several other factors in

248 addition to climate change, and the same is true for malaria. The impact that vector shifts have

249 on the global incidence of malaria will depend on several interacting (and often correlated)

250 factors, including deforestation and land degradation [41,42], insecticide resistance in

251 mosquitoes [43], emerging drug resistance [44,45], migration and human rights crises [46,47],

252 poverty [38], and conflict between malaria control and other aspects of sustainable development.

253 [49] In combination with these problems, the ability of malaria vectors to track shifting climate

254 optima at the pace of climate change is immensely problematic for control programs, and the

255 already stretched-thin healthcare infrastructure that many countries will struggle to maintain in

256 the face of climate change. New rapid diagnostics for malaria, and global efforts to integrate and

257 bolster mosquito surveillance, will help researchers tackle these threats, as will future efforts to

258 maintain and expand long-term datasets like the one we use here. [50-52] We recommend that

259 focusing some of these efforts in the highlands of eastern Africa and Madagascar, and on the

260 southern range limits of Anopheles gambiae complex, will likely be the strongest line of defense

261 against the expansion of malaria epidemics into new populations in a changing climate.

263 Author Contributions: EB initiated the idea for the study. CJC and EB collected data. CJC

264 performed all analyses. All authors contributed to the writing and editing of the manuscript.

266 Acknowledgements: We gratefully acknowledge Fausto Bustos, Casey Zipfel, and Zachary

267 Susswein for methodological advice, and thank the Bansal Lab for overall feedback. CJC

268 gratefully acknowledges the Georgetown Environment Initiative for funding support. 


\section{References}

271 1. Patz JA, Daszak P, Tabor GM, Aguirre AA, Pearl M, Epstein J, et al. Unhealthy landscapes: policy recommendations on land use change and infectious disease emergence. Environmental health perspectives. 2004; 1092-1098.

2. Carlson CJ, Burgio KR, Dougherty ER, Phillips AJ, Bueno VM, Clements CF, et al. Parasite biodiversity faces extinction and redistribution in a changing climate. Science Advances. 2017;3: e1602422.

3. Stephens PR, Altizer S, Smith KF, Alonso Aguirre A, Brown JH, Budischak SA, et al. The macroecology of infectious diseases: a new perspective on global-scale drivers of pathogen distributions and impacts. Ecology Letters. 2016;19: 1159-1171.

4. Chen I-C, Hill JK, Ohlemüller R, Roy DB, Thomas CD. Rapid range shifts of species associated with high levels of climate warming. Science. 2011;333: 1024-1026.

5. Bebber DP, Ramotowski MA, Gurr SJ. Crop pests and pathogens move polewards in a warming world. Nature climate change. 2013;3: 985-988.

6. Kraemer MU, Reiner RC, Brady OJ, Messina JP, Gilbert M, Pigott DM, et al. Past and future spread of the arbovirus vectors Aedes aegypti and Aedes albopictus. Nature Microbiology. 2019; 1.

7. Kraemer MU, Sinka ME, Duda KA, Mylne AQ, Shearer FM, Barker CM, et al. The global distribution of the arbovirus vectors Aedes aegypti and Ae. albopictus. Elife. 2015;4: e08347.

8. World Health Organization. World Malaria Report 2018. Geneva.: World Health Organization; 2018 Nov.

9. Siraj A, Santos-Vega M, Bouma M, Yadeta D, Carrascal DR, Pascual M. Altitudinal changes in malaria incidence in highlands of Ethiopia and Colombia. Science. 2014;343: 1154-1158.

10. Guerra CA, Gikandi PW, Tatem AJ, Noor AM, Smith DL, Hay SI, et al. The limits and intensity of Plasmodium falciparum transmission: implications for malaria control and elimination worldwide. PLoS medicine. 2008;5: e38.

11. Negash K, Kebede A, Medhin A, Argaw D, Babaniyi O, Guintran J, et al. Malaria epidemics in the highlands of Ethiopia. East African medical journal. 2005;82.

12. Garnham P. Malaria epidemics at exceptionally high altitudes. British medical journal. 1945;2: 45.

13. Lindsay S, Martens W. Malaria in the African highlands: past, present and future. Bulletin of the World Health Organization. 1998;76: 33.

14. Reiter P. Global-warming and vector-borne disease in temperate regions and at high altitude. The Lancet. 1998;351: 839-840.

15. Hay SI, Rogers DJ, Randolph SE, Stern DI, Cox J, Shanks GD, et al. Hot topic or hot air? Climate change and malaria resurgence in East African highlands. Trends in parasitology. 2002;18: 530-534.

16. Hay SI, Cox J, Rogers DJ, Randolph SE, Stern DI, Shanks GD, et al. Climate change and the resurgence of malaria in the East African highlands. Nature. 2002;415: 905.

17. Pascual M, Ahumada JA, Chaves LF, Rodo X, Bouma M. Malaria resurgence in the East African highlands: temperature trends revisited. Proceedings of the National Academy of Sciences. 2006;103: 5829-5834.

18. Alonso D, Bouma MJ, Pascual M. Epidemic malaria and warmer temperatures in recent decades in an East African highland. Proceedings of the Royal Society B: Biological Sciences. 2010;278: 1661-1669.

19. Gething PW, Van Boeckel TP, Smith DL, Guerra CA, Patil AP, Snow RW, et al. Modelling the global constraints of temperature on transmission of Plasmodium falciparum and P. vivax. Parasites \& vectors. 2011;4: 92.

20. Mordecai EA, Paaijmans KP, Johnson LR, Balzer C, Ben-Horin T, Moore E, et al. Optimal temperature for malaria transmission is dramatically lower than previously predicted. Ecology Letters. 2013;16: 22-30.

21. Ryan SJ, McNally A, Johnson LR, Mordecai EA, Ben-Horin T, Paaijmans K, et al. Mapping physiological suitability limits for malaria in Africa under climate change. Vector-Borne and Zoonotic Diseases. 2015;15: 718-725.

22. Johnson LR, Lafferty KD, McNally A, Mordecai E, Paaijmans KP, Pawar S, et al. Mapping the distribution of malaria: current approaches and future directions. Analyzing and modeling spatial and temporal dynamics of infectious diseases John Wiley \& Sons, New York, NY, USA. 2014; 189-209. 
23. Caminade C, Turner J, Metelmann S, Hesson JC, Blagrove MS, Solomon T, et al. Global risk model for vector-borne transmission of Zika virus reveals the role of El Niño 2015. Proceedings of the National Academy of Sciences. 2017;114: 119-124.

24. Kulkarni MA, Desrochers RE, Kajeguka DC, Kaaya RD, Tomayer A, Kweka EJ, et al. 10 years of environmental change on the slopes of Mount Kilimanjaro and its associated shift in malaria vector distributions. Frontiers in public health. 2016;4: 281.

25. Pinault LL, Hunter FF. New highland distribution records of multiple Anopheles species in the Ecuadorian Andes. Malaria journal. 2011;10: 236.

26. Tingley MW, Beissinger SR. Detecting range shifts from historical species occurrences: new perspectives on old data. Trends in ecology \& evolution. 2009;24: 625-633.

27. Kyalo D, Amratia P, Mundia CW, Mbogo CM, Coetzee M, Snow RW. A geo-coded inventory of anophelines in the Afrotropical Region south of the Sahara: 1898-2016. Wellcome open research. 2017;2: 57-57.

28. Ryan SJ, Carlson CJ, Mordecai EA, Johnson LR. Global expansion and redistribution of Aedes-borne virus transmission risk with climate change. PLoS Neglected Tropical Diseases. 2019;13: e0007213.

29. Adjemian JZ, Foley P, Gage KL, Foley JE. Initiation and spread of traveling waves of plague, Yersinia pestis, in the western United States. The American journal of tropical medicine and hygiene. 2007;76: 365-375.

30. Snow RW, Sartorius B, Kyalo D, Maina J, Amratia P, Mundia CW, et al. The prevalence of Plasmodium falciparum in sub-Saharan Africa since 1900. Nature. 2017;550: 515.

31. Wilson RJ, Gutiérrez D, Gutiérrez J, Martínez D, Agudo R, Monserrat VJ. Changes to the elevational limits and extent of species ranges associated with climate change. Ecology letters. 2005;8: 1138-1146.

32. Hickling R, Roy DB, Hill JK, Thomas CD. A northward shift of range margins in British Odonata. Global Change Biology. 2005;11: 502-506.

33. Hickling R, Roy DB, Hill JK, Fox R, Thomas CD. The distributions of a wide range of taxonomic groups are expanding polewards. Global change biology. 2006;12: 450-455.

34. Auer SK, King DI. Ecological and life-history traits explain recent boundary shifts in elevation and latitude of western North American songbirds. Global Ecology and Biogeography. 2014;23: 867-875.

35. Bates AE, Bird TJ, Stuart-Smith RD, Wernberg T, Sunday JM, Barrett NS, et al. Distinguishing geographical range shifts from artefacts of detectability and sampling effort. Diversity and Distributions. 2015;21: 13-22.

36. Loarie SR, Duffy PB, Hamilton H, Asner GP, Field CB, Ackerly DD. The velocity of climate change. Nature. 2009;462: 1052.

37. Sallares R, others. Malaria and Rome: a history of malaria in ancient Italy. Oxford University Press on Demand; 2002.

38. Newfield TP. Malaria and malaria-like disease in the early Middle Ages. Early Medieval Europe. 2017;25: 251-300.

39. Tjaden NB, Suk JE, Fischer D, Thomas SM, Beierkuhnlein C, Semenza JC. Modelling the effects of global climate change on Chikungunya transmission in the 21 st century. Scientific reports. 2017;7: 3813.

40. Lippi CA, Stewart-Ibarra AM, Loor MFB, Zambrano JED, Lopez NAE, Blackburn JK, et al. Geographic shifts in Aedes aegypti habitat suitability in Ecuador using larval surveillance data and ecological niche modeling: implications of climate change for public health vector control. PLoS neglected tropical diseases. 2019;13: e0007322.

41. Brock PM, Fornace KM, Grigg MJ, Anstey NM, William T, Cox J, et al. Predictive analysis across spatial scales links zoonotic malaria to deforestation. Proceedings of the Royal Society B. 2019;286: 20182351.

42. Potts M, Holland T, Erasmus B, Arnhold S, Athayde S, Carlson CJ, et al. Chapter 5: Land degradation and restoration associated with changes in ecosystem services and functions, and human well-being and good quality of life. In IPBES (2018): The IPBES assessment report on land degradation and restoration. Bonn, Germany,: Secretariat of the Intergovernmental Science-Policy Platform on Biodiversity and Ecosystem Services; 2018 pp. 341-432.

43. Ranson H, Lissenden N. Insecticide resistance in African Anopheles mosquitoes: a worsening situation that needs urgent action to maintain malaria control. Trends in parasitology. 2016;32: 187-196. 
44. Lwin KM, Imwong M, Suangkanarat P, Jeeyapant A, Vihokhern B, Wongsaen K, et al. Elimination of Plasmodium falciparum in an area of multi-drug resistance. Malaria journal. 2015;14: 319.

45. Corey VC, Lukens AK, Istvan ES, Lee MC, Franco V, Magistrado P, et al. A broad analysis of resistance development in the malaria parasite. Nature communications. 2016;7: 11901.

46. Mahmood SS, Wroe E, Fuller A, Leaning J. The Rohingya people of Myanmar: health, human rights, and identity. The Lancet. 2017;389: 1841-1850.

47. Jaramillo-Ochoa R, Sippy R, Farrell D, Cueva-Aponte C, Beltrán-Ayala E, Gonzaga J, et al. Effects of Political Instability in Venezuela on Malaria Resurgence at Ecuador-Peru Border, 2018. Emerging infectious diseases. 2019;25.

48. Willis DW, Hamon N. Eliminating malaria by 2040 among agricultural households in Africa: potential impact on health, labor productivity, education and gender equality. Gates open research. 2018;2.

49. Trisos CH, Alexander SM, Gephart JA, Gurung R, McIntyre PB, Short RE. Mosquito net fishing exemplifies conflict among Sustainable Development Goals. Nature Sustainability. 2019;2: 5.

50. Tao D, McGill B, Hamerly T, Kobayashi T, Khare P, Dziedzic A, et al. A saliva-based rapid test to quantify the infectious subclinical malaria parasite reservoir. Science translational medicine. 2019;11: eaan4479.

51. Fidock DA. A Breathprint for Malaria: New Opportunities for Noninterventional Diagnostics and Mosquito Traps? Oxford University Press US; 2018.

52. Tedrow RE, Rakotomanga T, Nepomichene T, Ratovonjato J, Ratsimbasoa A, Svenson GJ, et al. Novel Insights into Malaria Vector Surveillance in Madagascar Using a Quadrant Enabled Screen Trap (QUEST) and Bloodmeal Detection Assay for Regional Transmission (BLOODART). BioRxiv. 2019; 530758.

53. Clements CF, Worsfold NT, Warren PH, Collen B, Clark N, Blackburn TM, et al. Experimentally testing the accuracy of an extinction estimator: Solow's optimal linear estimation model. Journal of Animal Ecology. 2013;82: 345-354. 
394 Figure 1. Number of locality-species pairs by year increases rapidly, peaks during the GEMP, declines 395 after and returns in recent years.

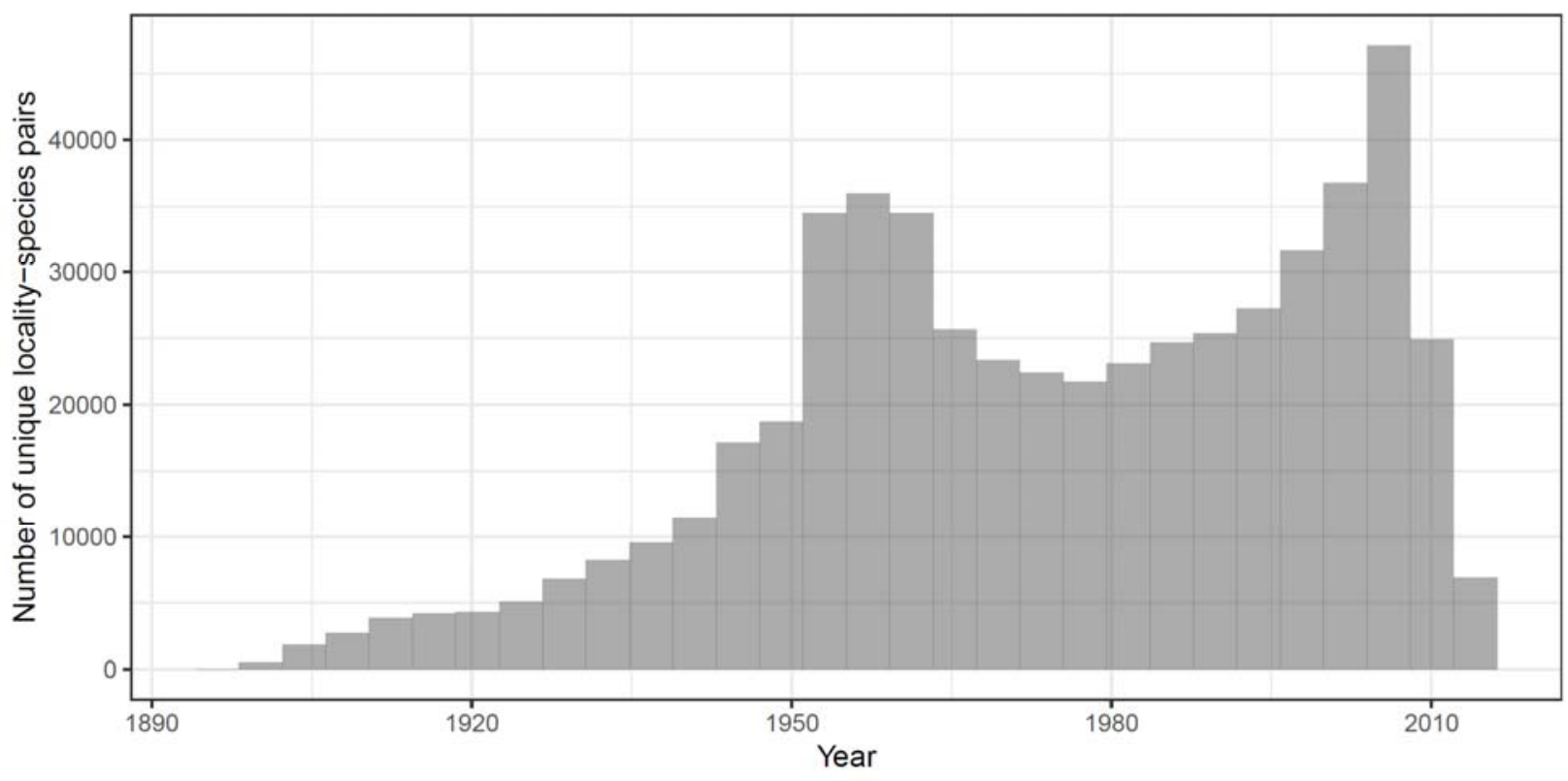

Figure 2. A century of range margin shifts in elevation and absolute latitude. Lines represent species'

A

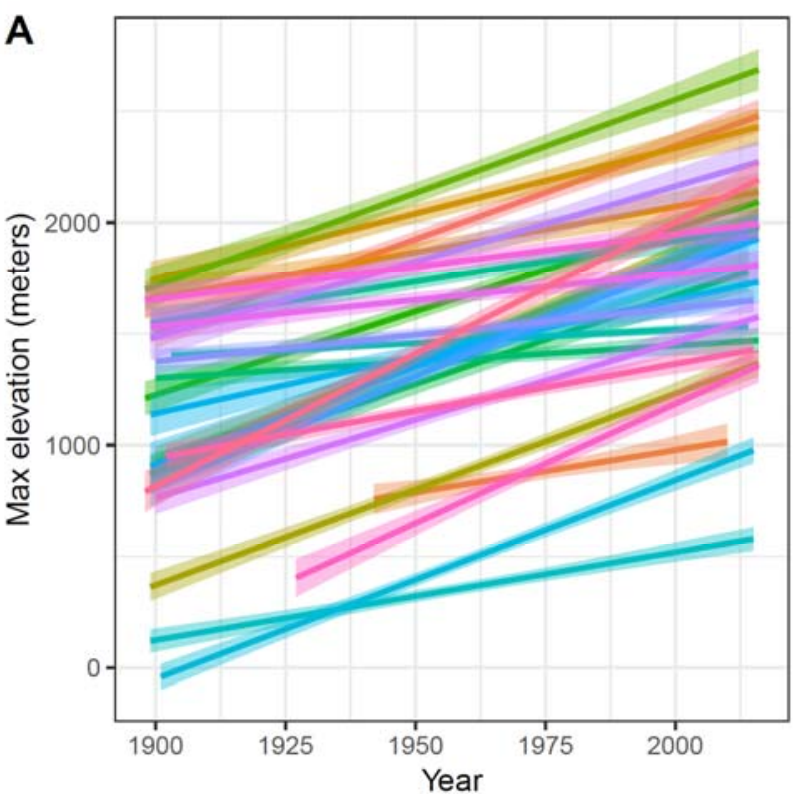

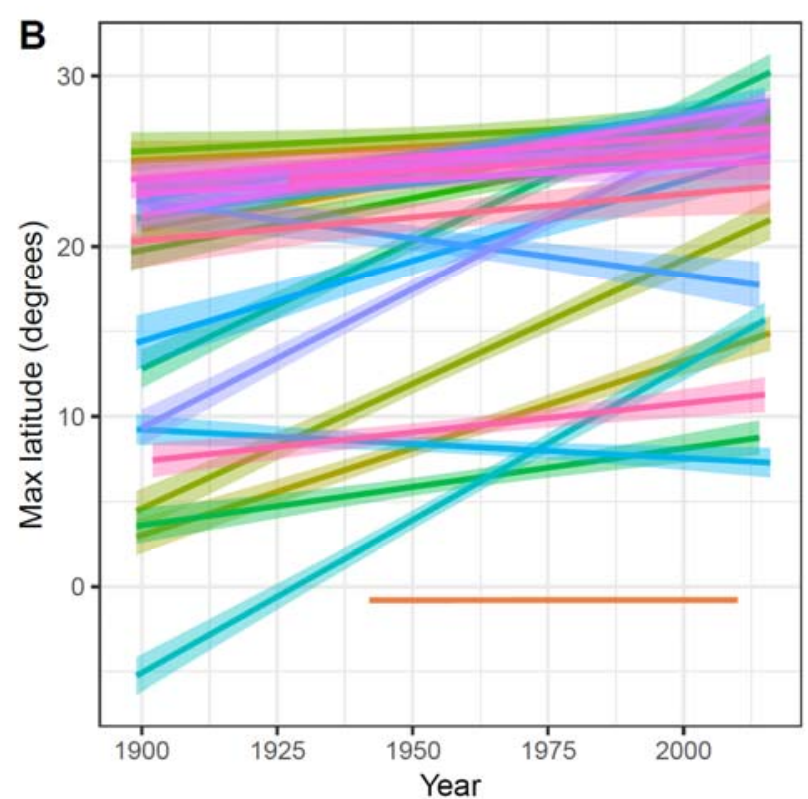


bioRxiv preprint doi: https://doi org/101101/673913; this version posted June 19, 2019. The copyright holder for this preprint (which was not certified by peer review) is the author/funder, who has granted bioRxiv a license to display the preprint in perpetuity. It is made available under aCC-BY 4.0 International license.

404 Figure 3. Latitudinal shifts estimated using the regression approach. (Units in left panel are degrees of 405 absolute latitude).
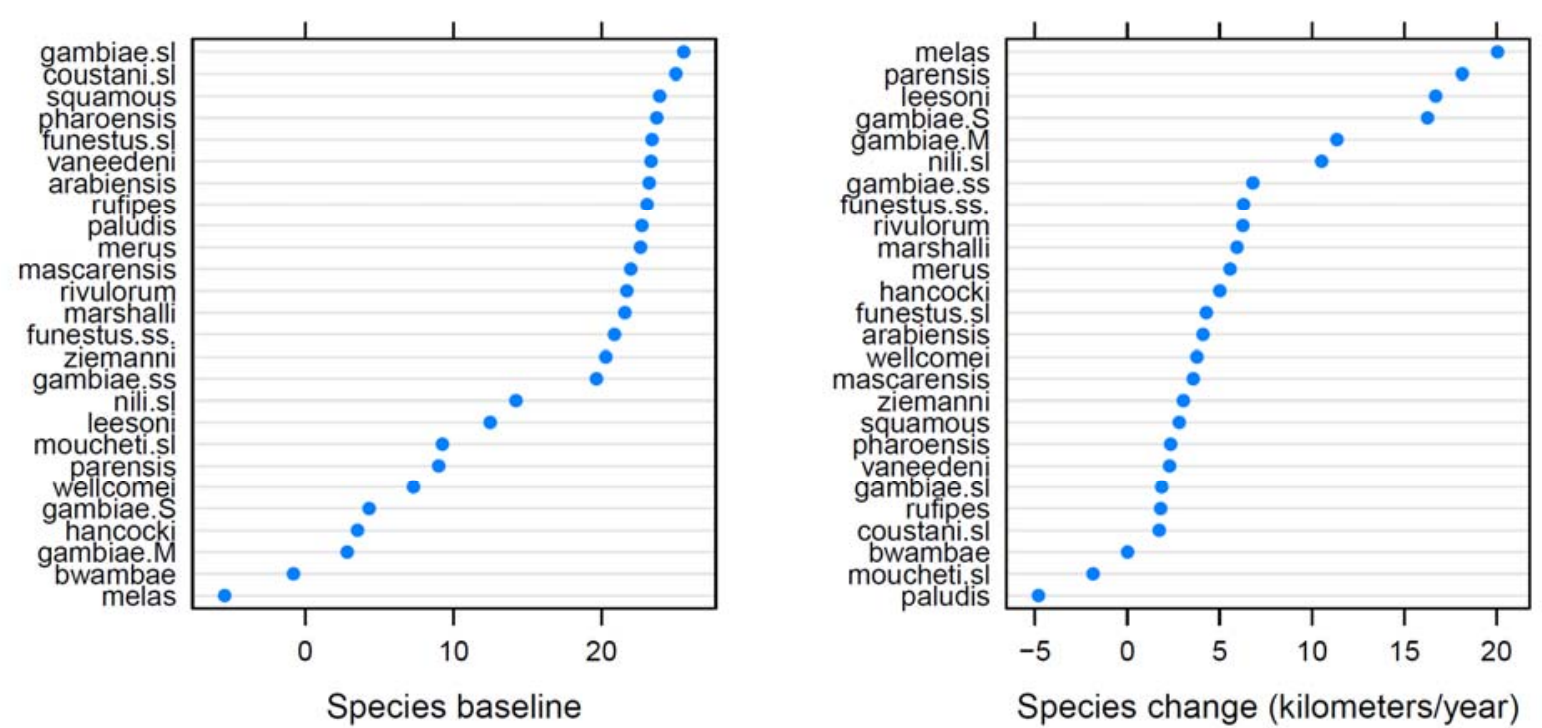

407 Figure 4. Elevational shifts estimated using the regression approach.
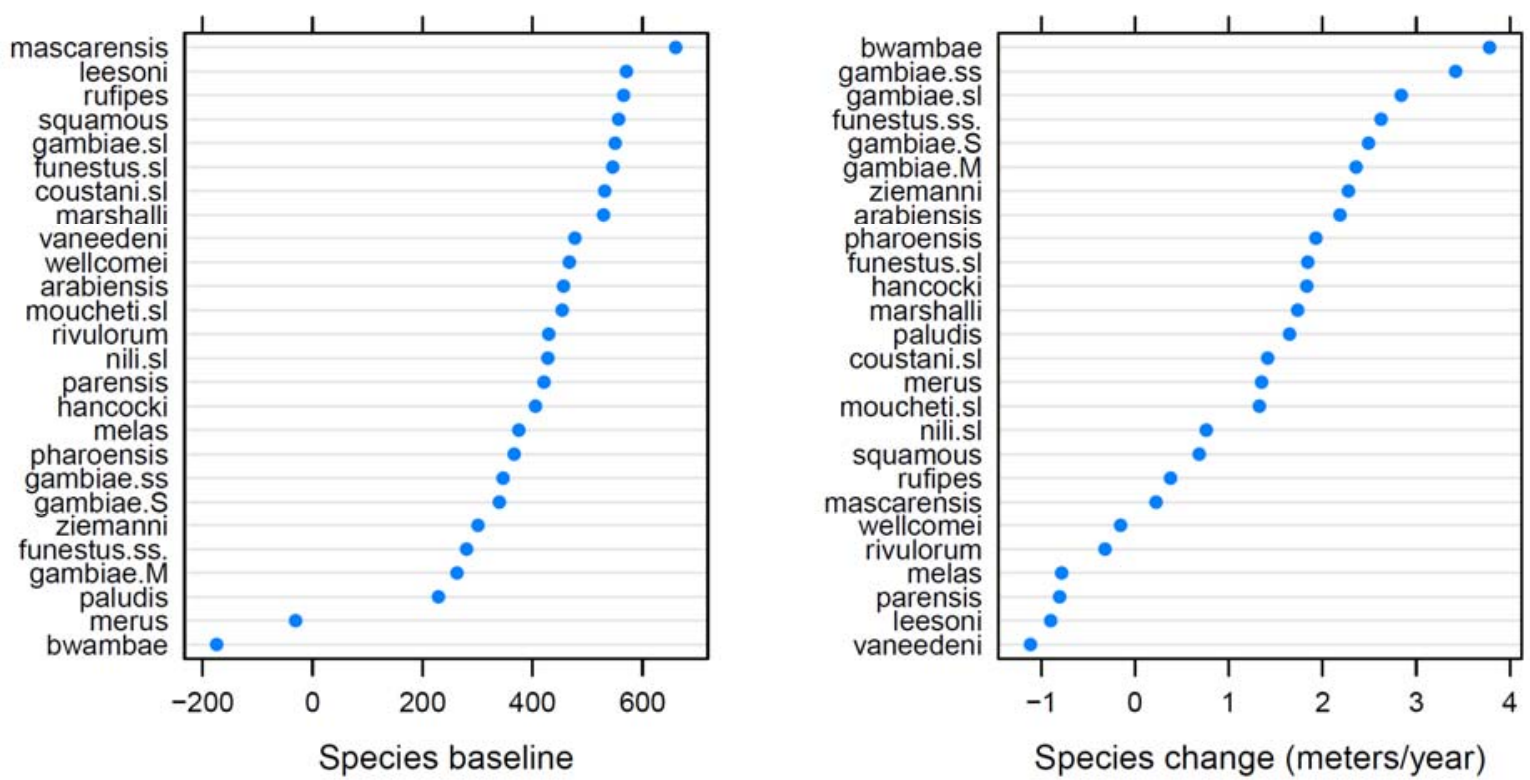
411 Figure 5. Maximum-based elevational and latitudinal shifts had no significant relationship ( $p=0.076)$,

412 implying the landscapes species are moving on may determine more about these shifts than intrinsic,

413 species-level dispersal capacity.

414

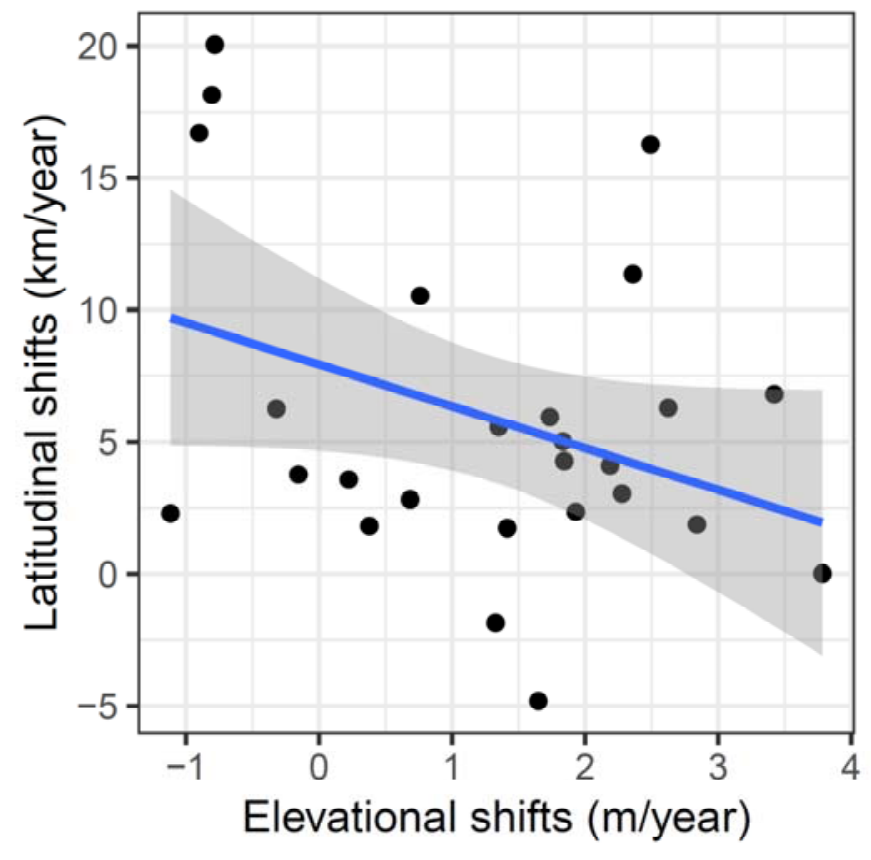

